\title{
Sexes of affected cases in sibships containing two or more members with anencephaly or spina bifida
}

\author{
WILLIAM H. JAMES \\ From the Department of Human Genetics and Biometry, The Galton Laboratory, \\ University College London, London NWI $2 \mathrm{HE}$
}

SUMMARY A study has been made of the sexes of the affected within sibships containing two 8 more members with anencephaly or spina bifida (ASB). There is no clear evidence for variation between ASB-prone women in their propensity to bear affected cases of one sex rather than the other. It is suggested that the point should be regarded as open until further data have settled toe issue.

It is well established that across populations (Knox, 1974), and within populations (Knox, 1974; James, 1979), the prevalence of anencephaly at birth correlates with the sex ratio of the affected, higher prevalences being associated with female cases. So one might try to explain the aetiology of anencephaly by proposing that it has two sorts of cause, viz (1) an environmental cause which affects predominantly females, and (2) another cause which may be genetic or environmental and which affects the sexes in roughly equal numbers.

If this were so, then it may be supposed that women who are known to be at high risk of bearing anencephalics are, in general, at risk on account of only one of these two sorts of cause and not both. If that were so then we might expect anencephalicprone women to be of two sorts, those inclined to bear cases of both sexes in about equal numbers, and those inclined to bear female cases. And if that were so, then the distribution of the sexes of the affected in sibships with more than one case would not be binomial, but would show Lexis variation (Edwards, 1960). For instance, if attention were confined to sibships containing exactly two anencephalics, there would be excesses of MM and FF pairs, and a deficit of MF pairs, as contrasted with chance expectation. It seemed worth testing this deduction.

\section{Materials and method}

Published reports were scanned for family histories containing two or more cases of anencephaly or spina bifida (ASB). Also, letters were despatched to workers who (to judge from their papers) might hân unpublished data of this sort.

Care has to be exercised in the analysis of sưog data. If we denote anencephaly by $\mathrm{A}$, and spima bifida by $S$, then the sex combinations within the three sorts of sibship AA, AS, and SS have to be examined separately. This is because it is known that (1) anencephaly has a lower sex ratio than spioga bifida, and (2) the same malformation tends केo recur within sibships (Smithells et al., 1968; Richara s et al., 1972; Carter, 1974).

Unless the data are separated in the manner suggested, any observed Lexis variation might simply be attributed to excesses of male-male spina bifida pairs and female-female anencephaly pairs 3

To assess whether the observed distributiogns departed from binomial expectation, the simplified maximum likelihood method of Robertson (195i) may be used.

Consider a sample of $\mathrm{N}$ sibships, each containixg exactly $n$ affected, where $n=m+f$ and $m$ is the number of males affected and $f$ the number of females affected. Then each sibship is assigned-a score

$\mathbf{K}=\frac{1}{2}\left[\frac{f(f-1)}{q^{2}}+\frac{m(m-1)}{p^{2}}-\frac{2 f m}{p q}\right] \underset{\sigma}{\stackrel{N}{N}}$

where $p$ is the proportion of males among the affected in the sample, and $q=1-p$. Now take

$$
\Sigma \mathrm{I}=\frac{N n(n-1)}{2 p^{2} q^{2}}
$$

Let the sum of the $N$ values of $\mathrm{K}$ be $\Sigma \mathrm{K}$ : then Robertson showed that $\Sigma K / \Sigma I$ is distribufed 306 
normally with sampling variance $1 / \Sigma \mathrm{I}$. For the present type of data, $\mathrm{K}$ is a particularly convenient statistic because $\Sigma \Sigma \mathrm{K} / \Sigma \Sigma \mathrm{I}$ is also distributed normally with sampling variance $1 / \Sigma \Sigma \mathrm{I}$, where summation may be carried out over sibships with different numbers of affected (and with different values of $p$ and $q$ ). Hence, one can test a whole range of material for a tendency towards over- or underdispersion.

\section{Results}

Tables 1, 2, and 3 give the frequencies of MM, MF, and FF pairs of affected within sibships. Table 1 suggests that (1) overall there is some tendency for anencephalics to be of the same sex within sibships, but that (2) this tendency is largely (if not wholly) because of the varying sex ratios of the affected across samples (corresponding, presumably, to the known variation in sex ratio of anencephalics across the country).

On the face of it, one might draw a similar inference from Table 2. However, there is little

Table 1 Combinations of sexes of affected within sibships containing exactly 2 anencephalics

\begin{tabular}{llll}
\hline Source & $M M$ & $M F$ & $F F$ \\
\hline Carter et al. (1968) & 0 & 3 & 5 \\
Carter and Evans (1973) & 2 & 7 & 9 \\
Williamson (1965) & 0 & 1 & 1 \\
Polman (1951) & 0 & 1 & 2 \\
Fuhrmann et al. (1971) & 1 & 0 & 0 \\
MacMahon et al. (1953) & 2 & 0 & 5 \\
Murphy (1936) & 1 & 2 & 2 \\
Czeizel and Revesz (1970) & 0 & 1 & 1 \\
Richards et al. (1972) & 3 & 5 & 10 \\
lsmail (1966) & 0 & 5 & 1 \\
Professor Carter & 0 & 2 & 6 \\
Mrs Fedrick & 0 & 3 & 2 \\
Professor Harris & 0 & 5 & 4
\end{tabular}

For the pooled data in this Table, $\Sigma \mathrm{I}=2187, \Sigma \mathrm{K}=32 \cdot 5, \mathrm{z}=0 \cdot 7$ : not significant. When the distributions are treated separately, $\Sigma \Sigma I=$ $2775 \cdot 7, \Sigma \Sigma K=-4.93, \mathrm{z}=-0.09$ : not significant.

Table 2 Combinations of sexes of affected within sibships containing exactly 2 spina bifidas

\begin{tabular}{lccc}
\hline Source & $M M$ & $M F$ & $F F$ \\
\hline Carter et al. (1968) & 8 & 11 & 2 \\
Carter and Evans (1973) & 3 & 5 & 3 \\
Williamson (1965) & 0 & 1 & 1 \\
Penrose (1946) & 0 & 3 & 2 \\
MacMahon et al. (1953) & 4 & 3 & 3 \\
Murphy (1936) & 0 & 2 & 1 \\
Czeizel and Revesz (1970) & 0 & 3 & 2 \\
Richards et al. (1972) & 4 & 5 & 10 \\
Professor Carter & 0 & 4 & 11 \\
Dr Lorber & 16 & 32 & 19 \\
Professor Harris & 3 & 4 & 3 \\
\hline
\end{tabular}

For the pooled data in this Table, $\Sigma \mathrm{I}=2758, \Sigma \mathrm{K}=81.48, \mathrm{z}=1.55$, $P=0.06$ (one-tailed). When the distributions are treated separately, $\Sigma \Sigma \mathrm{I}=3817, \Sigma \Sigma \mathrm{K}=10 \cdot 95, \mathrm{z}=0 \cdot 18$ : not significant.
Table 3 Combinations of sexes of affected within sibships containing exactly one spina bifida and one anencephalic

\begin{tabular}{llrr}
\hline Source & $M M$ & $M F$ & $F F$ \\
\hline Carter et al. (1968) & 1 & 4 & 11 \\
Carter and Evans (1973) & 2 & 13 & 6 \\
Williamson (1965) & 0 & 0 & 1 \\
Penrose (1946) & 0 & 1 & 1 \\
Polman (1951) & 0 & 2 & 0 \\
MacMahon et al. (1953) & 3 & 6 & 8 \\
Murphy (1936) & 0 & 1 & 1 \\
Czeizel and Revesz (1970) & 0 & 2 & 1 \\
Richards et al. (1972) & 2 & 8 & 4 \\
Book and Rayner (1950) & 0 & 1 & 0 \\
Professor Carter & 1 & 6 & 6 \\
Dr Lorber & 5 & 11 & 16 \\
Mrs Fedrick & 0 & 1 & 1 \\
Professor Harris & 1 & 19 & 6 \\
\hline
\end{tabular}

For the pooled data in this Table, $\Sigma I=2973, \Sigma K=-61 \cdot 3, z=-1 \cdot 12$ : not significant. When the distributions are treated separately, $\Sigma \Sigma I=$ 3283, $\Sigma \Sigma K=-57, z=-0.99$ : not significant.

evidence that the sex ratio of spina bifida varies between samples. If it does not, then it would be lezitimate to pool all the data in Table 2. If that is done, then the evidence for overdispersion may be assessed from a $\mathrm{z}$ score of $1 \cdot 55, \mathrm{P} \bumpeq 0 \cdot 06$ (one-tailed). Thus, even after pooling, the evidence is not strong.

The data in Table 3 are not of any obvious relevance to the aetiology of ASB. Since the sex ratio of anencephaly is lower than that of spina bifida, the distribution of the combinations of the sexes of pairs of affected (one spina bifida and one anencephalic) within sibships is subject to Poisson variation (not to be confused with Poisson distributions) (Edwards, 1960). It is a standard result in probability theory that Poisson variation is associated with a lower variance than the binomial with the same mean. Therefore, the subnormal dispersion of the distributions in Table 3 (and in the pooled data in that Table) may be ascribed to this.

\section{Discussion}

It is noteworthy that the test failed to detect significant Poisson variation in the distributions in Table 3. This suggests that the failure to find significant Lexis variation in Table 1 , at any rate, may be because of the weakness of the test, rather than the absence of the variation. We may be failing to find a needle that is in the haystack.

It seems likely that this problem will not be solved until more data are forthcoming. Accordingly, I should be grateful if anyone with further data on this point would send them to me.

I am grateful to Dr J. Lorber (Sheffield) for allowing me access to his data, and to Dr S. Rogers (Rugby) for coding them in a convenient form; to Professor 
C. O. Carter (Institute of Child Health, London) for forwarding to me the details of the sibships which were the basis of his paper with Dr Fraser Roberts (1967); to Mrs Fedrick for the details of the relevant sibships located in the Oxford Record Linkage Study Area; to Professor R. W. Smithells (University of Leeds) for drawing my attention to the data in the Liverpool Congenital Malformations Registry, and to Professor F. Harris (Institute of Child Health, Liverpool) for forwarding these data. Dr A. R. Jonckheere (University College London) was generous with help and encouragement. I am supported by the National Fund for Research into Crippling Diseases.

\section{References}

Book, J. A., and Rayner, S. (1950). A clinical and genetical study of anencephaly. American Journal of Human Genetics, 2, 61-84.

Carter, C. O. (1974). Clues to the aetiology of neural tube malformations. Developmental Medicine and Child Neurology, Suppl. 32, 3-15

Carter, C. O., David, P. A., and Laurence, K. M. (1968). A family study of major central nervous system malformations in South Wales. Journal of Medical Genetics, 5, 81-106.

Carter, C. O., and Evans, K. (1973). Spina bifida and anencephalus in Greater London. Journal of Medical Genetics, 10, 209-234.

Carter, C. O., and Fraser Roberts, J. A. (1967). The risk of recurrence after two children with central nervous system malformations. Lancet, 1, 306-308.

Czeizel, A., and Revesz, C. (1970). Major malformations of the central nervous system in Hungary. British Journal of Preventive and Social Medicine, 24, 205-222.

Edwards, A. W. F. (1960). The meaning of binomial distribution. Nature, 186, 1074.
Fuhrmann, W., Seeger, W., and Bohm, R. (1971). Apparen monogenic inheritance of anencephaly and spina bifida inta kindred. Humangenetik, 13, 241-243.

Ismail, S. R. (1966). A Genetical Study of Anencephath. Ph.D Thesis, University of London.

James, W. H. (1979). The sex ratio in anencephaly. Journa Medical Genetics, 16, 129-133.

Knox, E. G. (1974). Twins and neural tube defects. Brit $\frac{\mathrm{s}}{\mathrm{S}} \mathrm{h}$ Journal of Preventive and Social Medicine, 28, 73-80.

MacMahon, B., Pugh, T. F., and Ingalls, T. H. (1953). Anencephalus, spina bifida and hydrocephalus: incidene, related to sex, race, and season of birth and incidence $\overrightarrow{\mathrm{d}}$ siblings. British Journal of Preventive and Social Medicine, 7, 211-219.

Murphy, D. P. (1936). The duplication of congenital mâ. formations in brothers and sisters and among otter relatives. Surgery, Gynecology and Obstetrics, 63, 443-4.

Penrose, L. S. (1946). Familial data on 144 cases of anencephaly, spina bifida and congenital hydrocepha円P. Annals of Eugenics, 13, 73-98.

Polman, A. (1951). Anencephaly, spina bifida a.t్t hydrocephaly. Genetica, 25, 29-78.

Richards, I. D. G., McIntosh, H. T., and Sweenie, S. (1972). A genetic study of anencephaly and spina bifida in Glasgow. Developmental Medicine and Child Neurology, 14, 626-639.

Robertson, A. (1951). The analysis of heterogeneity in the binomial distribution. Annals of Eugenics, 16, 1-15.

Smithells, R. W., D'Arcy, E. E., and McAllister, E. F. (1968s). The outcome of pregnancies before and after the birth of infants with nervous system malformations. Developmen Medicine and Child Neurology, Suppl. 15, 6-10.

Williamson, E. (1965). Incidence and family aggregation of major congenital malformations of the central nervous system. Journal of Medical Genetics, 2, 161-172.

Requests for reprints to Dr W. H. James, Departme⿻⿱⺈口𧰨口巾 of Human Genetics and Biometry, The Galton Laboratory, University College London, Wolfse्gn House, 4 Stephenson Way, London NW1 2HE. 